\title{
La reforma al derecho de la responsabilidad contractual: consecuencias específicas de la constitucionalización del Derecho Privado
}

\section{The Reform the Law of Contractual Respon- sibility}

JOAQUÍN ACOSTA*

Fecha de recepción: 1 de abril de 2009 Fecha de aprobación: 30 de abril de 2009

\section{Resumen}

La promulgación de la Constitución de 1991 en Colombia ha generado una reforma fundamental en el Derecho colombiano. Se ha dado lugar a la juridización de la Constitución, antes considerada esencialmente un programa político. Esta fenomenología ha dado lugar a una crisis de la concepción tradicional del derecho. Tal tendencia tiene que ver directamente con el debate Hart-Dworkin: el poder creador del juez, o la distinción entre reglas y principios. El régimen de la responsabilidad civil no ha sido ajeno a este proceso. Las perspectivas que se abren ante esta nueva realidad ofrecen interesantes oportunidades para modernizar el derecho de la responsabilidad ante las nuevas realidades sociales y económicas.

\section{Palabras clave}

Constitucionalización, neo-constitucionalismo, juridización.

Profesor de la Maestría en Contratación Pública y Privada de la Universidad Santo Tomás de Bogotá. Con posgrado (DSU) en Derecho Comercial de la Universidad de París II (Panthéon-Assas); magíster en Derecho Privado General y Candidato a Doctor en Derecho de la Universidad de París II. Profesor en pregrado de obligaciones y contratos en las Universidades Santo Tomás y Sergio Arboleda. Correo electrónico: joaquinacosta@ usantotomas.edu.co 


\begin{abstract}
The promulgation or public announcement of the Colombian constitution of 1991 has generated a fundamental reform to the Colombian law. Juridization has born. This reality has generated a reshuffle of the traditional conception of law. This tendency is connected with Hart-Dworkin debate: the creative power of juge, or distinction between principles and rules. The responsability regime also has been touched by this news realitys. The perspectives than are open afford interesting opportunities to modernize responsibility law in view of the news situations.
\end{abstract}

\title{
Key words
}

Constitution, Juridization, New cosntitution.

\section{INTRODUCCIÓN}

La palabra "constitucionalización" podría indicar simplemente un sinónimo de "fundamentos constitucionales". En realidad, se trata de un fenómeno jurídico mucho más complejo que la reiteración de la supremacía de la norma constitucional sobre cualquier texto legal. Para entender cabalmente la naturaleza y alcance de este término es imprescindible entender que el Derecho de la Responsabilidad, a pesar de su apariencia puramente técnica, se encuentra en estrecho vínculo con las ideologías políticas y económicas de cada contexto histórico. Siempre se nos ha tratado de presentar el Derecho colombiano privado como un instrumento heredado de manera intacta del Derecho Romano. Ello no es exacto debido a que cada época histórica ha aportado a la concepción de lo jurídico, no solamente en materia constitucional, sino también en términos ius privatistas.

La comprensión de esta realidad tiene fuerte vocación para atender algunas voces que consideran que nuestra Corte Constitucional debe ser eliminada para volver al esquema tradicional de una sala constitucional dentro de una Corte Suprema de Justicia. Tales opiniones alegan que esta propuesta de retorno al pasado se fundamenta en la necesidad de corregir los supuestos yerros en que ha incurrido este tribunal, principalmente, atentar contra la seguridad jurídica y consagrar de facto un gobierno de los jueces.
En consecuencia, lo más procedente es, en primer lugar, partir del marco conceptual en el que se ha desenvuelto el denominado neo-constitucionalismo contemporáneo: el debate Hart-Dworkin y la evolución en el esquema de las fuentes del Derecho.

\section{EL COMIENZO DEL PENSAMIENTO JURÍDICO CONTEMPORÁNEO: EL DEBATE HART-DWORKIN}

En 1961 H.L.A. Hart publicó El concepto de Derecho (1961: 1963). Esta obra dio inicio a un fecundo proceso de reflexión en la teoría jurídica y el papel del juez en el Derecho (Rodríguez, 2008, p. 15). El punto de partida de esta propuesta se encuentra en los trabajos de J.L. Austin en Oxford, así como de Ludwig Wittgeinstein en Cambridge (Hart, 1963, p. 20). Desde esta plataforma Hart emprendió una crítica a la teoría positivista, cuyas raíces se remontan a los trabajos de Jeremías Bentham a finales del siglo XVIII. Es menester entonces recordar que los dos pilares del positivismo jurídico son:

- Separación tajante entre lo que el derecho "es" y lo que el derecho "debe ser";

- Énfasis en desligar derecho de moral.

Hart rechazó este criterio para renovar la perspectiva positivista a partir de la existencia de límites al poder legislativo, el papel de la costumbre como fuente 
del Derecho, así como el régimen de instituciones del Derecho Privado, como el acto jurídico, en tanto que entes normativos. Todo lo anterior para definir criterios de validez (entiéndase de legitimidad) al sistema jurídico. Entre las consecuencias más importantes de estos trabajos tenemos la elaboración de la denominada regla de reconocimiento.

La reformulación hartiana del positivismo dio inicio a un amplio debate, en el que hubo posiciones tanto a favor como en contra. A partir de 1963, el heredero de la cátedra de Filosofía del Derecho de H.L.A Hart en la Universidad de Oxford y catedrático en la Universidad de Nueva York, Ronald Dworkin, obtuvo un lugar protagónico entre las posiciones críticas al planteamiento hartiano. Durante unos quince años Dworkin publicó una serie de artículos que fueron el basamento de su famoso libro Taking Rights Seriously (1984), publicado en 1977. Estos trabajos dieron origen a un debate internacional sobre la distinción entre reglas y principios (Alexy, 2003, p. 93). Desde entonces han surgido nuevas implicaciones acerca de la concepción del sistema jurídico, así como de la relación entre derecho y moral.

Igualmente, Hispanoamérica ha sido influenciada por los trabajos reseñados con anterioridad. Acontecimientos jurídicos recientes han motivado la traducción y estudio de los escritos tanto de Hart como de Dworkin: el establecimiento de un tribunal constitucional en España en 1978, así como en Colombia en 1991 ha dado lugar a la juridización de la Constitución, antes considerada esencialmente un programa político (Rodríguez, 2008, p. 17). Esta fenomenología ha dado lugar a una crisis de la concepción tradicional del Derecho.

En Colombia, la Constitución de 1991 ha dado lugar a que se haya acuñado el término neo-constitucionalismo, cuyo contenido tiene que ver directamente con el debate Hart-Dworkin: el poder creador del juez, o la distinción entre reglas y principios (Cepeda, 1992, p. 20). A manera de ejemplo, es pertinente recordar el caso relacionado con la exe- quibilidad de una ley que penalizaba el porte y uso de dosis personales de estupefacientes (Sentencia C-221/94); semejante evolución se debe a que la constitucionalización equivale a la inserción en la Carta Política de las obligaciones fundamentales correlativas a cargo del Estado (Carrillo, 2003, p. 235) En realidad, todo este proceso y sus implicaciones en el Derecho de la Responsabilidad se entenderán mejor si lo abordamos desde la perspectiva de las fuentes jurídicas.

\section{FUENTES DEL DERECHO DE LA RESPONSABILIDAD}

En general, fuente es el principio u origen de una cosa, el lugar donde nace o se produce algo. Es el principio, el fundamento, el origen, la causa o la explicación de una cosa. Cuando hablamos de "fuentes", nos referimos al origen del Derecho de la Responsabilidad, a los fenómenos que le dan nacimiento, a las manifestaciones de la voluntad humana o a los usos o prácticas sociales que lo generan: al origen del propio objetivo de esta teoría. Ahora bien, no sobra recordar que en materia jurídica las fuentes del Derecho tienen su propia clasificación y comprensión. La Corte Constitucional señala a este respecto: Las fuentes del derecho se clasifican en
fuentes materiales y fuentes formales.

Las primeras hacen relación a los hechos y circunstancias que hacen producir el derecho, como el acaecer social, económico, político, esto es, la realidad misma.

Las segundas hacen relación a los cauces por los cuales se expresa el derecho.

Son fuentes formales la ley -material-, la jurisprudencia, la costumbre, la equidad, los principios generales del derecho y la doctrina.

En Colombia, empero, la tradición jurídica secular siempre ha establecido que sólo es fuente formal principal de derecho la ley en sentido material, esto es, la Constitución, la ley, los decretos y demás actos jurídicos. Las otras fuentes sólo son criterios auxiliares (Sentencia C-104/93). 
En virtud de la anterior exposición, nos centraremos en la actual comprensión que merece nuestra Constitución Política como fuente formal.

\section{La Constitución Política de Colombia, fuente fundamental}

Para la óptica clasicista, la fuente esencial del Derecho de la Responsabilidad era la ley. Los redactores del Código Civil otorgaron en términos generales a los contratantes una gran libertad de acción jurídica. Es por ello que la mayor parte de leyes que rigen a la responsabilidad contractual presentan un carácter supletivo de la voluntad individual (Terre, Smiler \& Lequette, 1999). Esta primacía legislativa ha sido limitada en Derecho por nuestra Constitución de 1991; por razones de jerarquía de normas, no es posible al legislador desconocer ni vulnerar principios que tengan rango constitucional. Esta visión le ha permitido a nuestra Corte Constitucional declarar la inexequibilidad o la exequibilidad condicionada de las disposiciones legislativas que atenten contra postulados constitucionales. En efecto, nuestro alto tribunal constitucional ha declarado (Sentencia C-491/00, expediente D-2653, MP Alejandro Martínez Caballero):

[...] la Carta [...] no sólo persigue un orden justo sino que expresamente condena el enriquecimiento ilícito [...] ya que las categorías del derecho privado deben ser interpretadas a luz de los principios y valores constitucionales.

La Corte coincide con esas perspectivas en que no sólo el derecho privado sino todas las ramas del derecho deben ser reinterpretadas a la luz de los principios y valores constitucionales, pues si la Constitución es norma de normas, y debe aplicarse de preferencia a las otras disposiciones (CP art. $4^{\circ}$ ), es indudable que ha operado una cierta constitucionalización del derecho ordinario" (NFT).

\section{La constitucionalización del Derecho de la Responsabilidad Contractual}

Entonces, se puede verificar un típico fenómeno contemporáneo en relación con las fuentes del contrato: la constitucionalización del Derecho Privado, como fenómeno específico de la constitucionalización del Derecho ordinario, en general. Mientras que la teoría clásica del Derecho preconiza que en aras de preservar la seguridad jurídica lo mejor es que el juez de constitucionalidad mantenga su discurso en un nivel abstracto, para de esta manera separar Derecho Constitucional y Derecho ordinario ${ }^{1}$, de tal suerte que las diferentes interpretaciones no se enfrenten y den lugar a confusiones entre los justiciables, el Derecho contemporáneo exige que los tribunales constitucionales obliguen al juez ordinario de responsabilidad a reinterpretar las categorías tradicionales a la luz de los valores constitucionales, el primero de ellos la construcción de un orden jurídico justo.

Tales visiones antagónicas han dejado un fuerte impacto no sólo en la dogmática jurídica, sino también en la vida social nacional. Hablamos concretamente del fenómeno denominado por nuestros medios de comunicación "choque de trenes", en el que se ha visto un enfrentamiento directo entre la Corte Constitucional, Corte Suprema de Justicia y Consejo de Estado. El basamento ideológico subyacente a esta crisis jurídica radica en el enfrentamiento entre las ópticas clásica y contemporánea. La Corte Suprema, así como el Consejo de Estado preponderantemente han sido (dentro de ondulaciones y hesitaciones jurisprudenciales) los adalides de la visión clásica, por ser los guardianes de Códigos pertenecientes al siglo XIX; nuestra Constitución, promulgada a finales del siglo $\mathrm{XX}$, por el contrario, consagra la perspectiva posmoderna. Posterior-

1 A modo de ejemplo, es pertinente recordar las jornadas de Viena de la Asociación Alemana de Profesores de Derecho del Estado en 1928, en las cuales Hans Kelsen denunció el peligro consistente en que principios de contenido impreciso como la libertad o igualdad otorgaran a la Corte Constitucional un poder omnímodo. 
mente se verificará que las sentencias de nuestro Tribunal Constitucional, lejos de ser elaboraciones exóticas, se encuentran en realidad en consonancia con las tendencias contemporáneas de los demás derechos de tradición romanista, que están reinterpretando su normatividad ordinaria a la luz de los valores constitucionales, tal y como acontece con los países de la Unión Europea. En ese continente ya se ha entendido que si la Constitución Política es norma de normas, la Corte Constitucional debe ser la "Corte de Cortes". Sólo de esta manera se garantizará la seguridad jurídica dentro del esquema posmoderno del Derecho.

\section{Reseña histórica de la constitucionalización}

Esta concepción para nada es una creación arbitraria de nuestra Corte Constitucional. Por el contrario, la idea de reinterpretar el Derecho ordinario a la luz de los valores constitucionales se encuentra en perfecta armonía con las tendencias posmodernas de la dogmática jurídica. En efecto, esta fenomenología nació en Alemania y se concretó en sus bases, gracias al celebérrimo caso Luth, en 1958. Este proceso versaba entre un director de cine llamado Veit Harlan y el presidente de la oficina de prensa de Hamburgo, apellidado Lüth (Añexy, 2003, p. 43). En diversas oportunidades el segundo había criticado ácidamente a Harlan por dirigir películas antisemitas; incluso, llegó a incitar el boicot de este tipo de cintas.

Mientras que los tribunales de instancia consideraron que la conducta del periodista vulneraba las buenas costumbres del art. 826 del BGB (Código Civil Alemán), la Corte Constitucional alemana concedió la tutela interpuesta por Lüth, arguyendo que su conducta era un ejercicio legítimo de la libertad de expresión, la cual también se aplicaba en el ámbito del derecho privado. Esta nueva concepción de lo constitucional amerita un breve repaso acerca de la ley como fuente del Derecho.

\section{La ley, fuente primaria}

En este contexto, por leyes parece razonable entender todas las normas jurídicas válidamente creadas, sujetas a la Constitución (Sentencia C-083/95). En estrecha concordancia, el artículo $4^{\circ}$ de nuestro Código Civil establece: "Ley es una declaración de la voluntad soberana manifestada en la forma prevenida en la Constitución Nacional. El carácter general de la ley es mandar, prohibir, permitir o castigar".

Al momento de exponer la ley como fuente de Derecho, la mayoría de textos se dedican a presentar las diferentes definiciones que observa el vocablo "ley", señalar que tiene una naturaleza general y abstracta, aclarar que ésta no debe ser desconocida ni por los particulares ni por los funcionarios estatales; que la ignorancia de la ley no sirve de excusa (Código Civil, art. 9), que la ley es obligatoria y surte sus efectos desde el día designado por ella misma, y en todo caso desde su promulgación (Código Civil, art. 11) y que en caso de violación el responsable debe ser sancionado ${ }^{2}$.

Sin embargo, se echa de menos una exposición clara sobre la finalidad con la cual se creó y desarrolló la ley, especialmente en la época moderna. La importancia que observa la comprensión de la ley como fuente del Derecho de la Responsabilidad radica precisamente en el correcto entendimiento del objetivo, de la finalidad que observa. Es por ello que inicialmente veremos la dimensión moderna del fenómeno legislativo, y consecutivamente veremos la ley de responsabilidad en su dimensión posmoderna.

2 Código Civil, artículo 60: "La sanción legal no es sólo la pena, sino también la recompensa; es el bien o el mal que se deriva como consecuencia del cumplimiento de sus mandatos o de la transgresión de sus prohibiciones.

En materia civil son nulos los actos ejecutados contra expresa prohibición de la ley, si en ella misma no se dispone otra cosa. Esta nulidad, así como la validez y firmeza de los que se arreglan a la ley, constituyen suficientes penas y recompensas, aparte de las que se estipulan en los contratos". 


\section{La ley moderna: el Código Civil colombiano}

En el Derecho moderno se verificó que su principal característica radica en el fenómeno de la codificación. En materia de Derecho Privado, nuestro ordenamiento jurídico nacional adoptó precisamente el Código Civil colombiano, el cual, a su vez, tiene su antecedente en el Código de Chile, que fue adoptado en nuestro país por medio de la Ley 57 de 1887. El Código Civil de la República de Chile (también conocido como Código de Bello) fue obra del jurista chileno-venezolano Andrés Bello, sin duda alguna uno de los más grandes humanistas de América Latina ${ }^{3}$. El Código de Bello sirvió de inspiración a muchos otros Códigos Civiles de Latinoamérica aparte de Colombia. Es por ello que no pocos doctrinantes consideran al Código de Bello como la obra jurídica más importante de América Latina.

En materia de obligaciones y contratos, la principal fuente de inspiración del Código Civil chileno fue el Código Civil francés, igualmente conocido como el Código de Napoleón. Para efectos de una mejor comprensión de nuestras raíces jurídicas es conveniente entender las razones por las cuales don Andrés Bello -al menos en materia de responsabilidad, obligaciones y contratos- adoptó como modelo al Código de Napoleón.

\section{El Código Civil francés y su influencia internacional}

Desde el siglo XVII, la Francia de Luis XIV desplazó progresivamente a España en la hegemonía europea. Las academias literarias y científicas se multiplican, y se constituyen en los focos del futuro iluminismo. Con el tiempo la Europa refinada habla francés. Se trata de una época de reflexión y cuestionamiento; gracias a nombres tales como Montesquieu, Diderot, Voltaire o Rousseau se desarrollaron, entre otros, los siguientes ideales:

3 http://www.andresbello.org/article.php3?id_article=18\&id_ rubrique $=9$
- Eliminación de las desigualdades sociales.

- Eliminación de la intolerancia religiosa: cada ciudadano puede profesar una religión diferente a la del Estado.

- Reforma de las estructuras políticas y jurídicas.

Las anteriores ideas produjeron nuevas concepciones jurídicas: así por ejemplo, el marqués de Beccaria, economista y jurista influenciado por los filósofos franceses, denunció en su obra De los delitos y las penas (1764), las aberraciones de la justicia criminal de su época, la cual es calificada como una monstruosa producción de los siglos más bárbaros. Reclamando la abolición de la tortura y la pena de muerte, inspirará la reforma del Derecho Penal en numerosos países de tradición jurídica romanista.

Sin embargo, la influencia iluminista francesa desborda el ámbito del Derecho Penal; hablamos de uno de los textos fundadores de la democracia en el mundo: la Declaración de los Derechos del Hombre y del Ciudadano de 1789, texto que es igualmente el preámbulo de la Constitución francesa. En Colombia fue traducida por nuestro prócer de la independencia, don Antonio Nariño; esta declaración resume el individualismo liberal desarrollado hasta esa época. Por las circunstancias ideológicas de la Modernidad, se trata de una proclamación universal, un texto cuyo objetivo preciso es abolir la ideología del Ancien régime (Antiguo régimen) de sustrato medieval y perdurar eternamente. Se trata entonces de la concreción de la filosofía de las Luces del siglo XVIII, orientada hacia el universalismo y la abstracción.

Esta Declaración Universal pretende enumerar los derechos naturales e imprescriptibles del hombre, entre los cuales se encuentran: libertad, propiedad, seguridad y resistencia a la opresión. Estos imperativos marcaron una nueva etapa del Derecho y consolidaron la tradición jurídica francesa y, por 
tanto, la colombiana. Estrechamente vinculado al principio de legalidad encontramos el imperativo de seguridad jurídica, eje fundamental para la correcta comprensión de la teoría clásica de la responsabilidad contractual.

\section{LA SEGURIDAD JURÍDICA}

Esta noción ha sido el concepto axial de la teoría moderna no sólo de la responsabilidad civil, sino también del Derecho en todas sus ramas y especialidades. Gracias a este imperativo se han cuestionado las recientes tendencias tanto doctrinales como jurisprudenciales de nuestros jueces y en especial de la gestión de nuestra Corte Constitucional. Ha sido un escenario común por parte de determinados sectores clamar por la eliminación de la Corte Constitucional y volver al tradicional sistema de una sala constitucional, dependiente de nuestra Corte Suprema de Justicia. Esto en virtud del atentado que nuestro alto tribunal constitucional habría efectuado contra la seguridad jurídica.

Pero, ien qué consiste realmente la seguridad jurídica? El Diccionario de la lengua española ${ }^{4}$ define a la seguridad jurídica como la "Cualidad del ordenamiento jurídico, que implica la certeza de sus normas $y$, consiguientemente, la previsibilidad de su aplicación. En España es un principio constitucional". Por tanto, dos notas esenciales caracterizan este principio: certeza y previsibilidad. Si los justiciables sabemos con seguridad qué está permitido y qué es lo prohibido, podremos entonces prever la consecuencia jurídica de nuestro actuar. De esta manera será fácil identificar si el funcionario estatal competente ha incurrido en arbitrariedad por castigar determinado comportamiento por ejemplo, imponer una multa por conducir el vehículo automotor por la derecha, respetando el límite de velocidad y las normas de tránsito en general, es atentatorio de la seguridad jurídica.

4 www.rae.es
En síntesis, el imperativo de seguridad jurídica - que en Colombia también es principio (Sentencia C-104/93)- es la garantía conferida al justiciable para saber cuáles son las reglas de juego, y las consecuencias que se desprenden de su cumplimiento o incumplimiento. Es un imperativo encaminado a impedir la arbitrariedad del funcionario estatal, juez incluido. Todo lo que implique lucha contra la arbitrariedad conlleva de suyo protección de la libertad. Es por ello que se ha establecido:

\begin{abstract}
La seguridad jurídica, en su sentido positivo, se da cuando existen normas reguladoras de la conducta humana, siempre y cuando éstas sean públicas, previas, claras, manifiestas, y se apliquen a todos por igual, por instituciones independientes que hagan parte de una estructura democrática.

Entre la seguridad y la libertad de la persona se da un vínculo inseparable. Es difícil pensar en seguridad sin libertad, y también difícil imaginarse una libertad sin seguridad para uno mismo y para los demás (Frühling, s.f.).
\end{abstract}

Esta visión ha sido ampliamente reconocida por nuestra jurisprudencia nacional. Así, por ejemplo, nuestra Corte Constitucional explica (Sentencia C-549/93):

La seguridad jurídica es requisito para la configuración del orden público. Si no hay una estabilidad en cuanto a la consecuencia jurídica, obviamente no pueden los destinatarios de la ley estar gozando del derecho a la seguridad. La incertidumbre ante la actuación del Estado impide la seguridad debida a cada uno de los asociados (NFT).

En consecuencia, a pesar de los ingentes debates en torno a la seguridad jurídica que se desarrollan y desarrollarán a futuro, hay un elemento conceptual generalmente aceptado: la ley ha sido el mecanismo para promover la seguridad jurídica, la cual, a su vez, tiene como finalidad principal combatir las arbitrariedades de los diferentes funcionarios y agentes del Estado. Todo en aras de la libertad. Ahora bien, la libertad no es un derecho absoluto, 
sino relativo; en otras palabras, la libertad tiene límites. En consecuencia, si la libertad tiene límites y es relativa, la seguridad jurídica también, por cuanto libertad y seguridad jurídica son "hermanas siamesas". Por consiguiente, los imperativos de certeza así como de previsibilidad son relativos, nunca absolutos; hay límites. Una de las principales consecuencias de esta realidad conceptual es que dentro de la seguridad jurídica hay un espacio indeterminado de acción que el Derecho de corte democrático otorga a los particulares. No puede ser de otro modo en aras de salvaguardar la libertad. Es por ello que nuestra Corte Constitucional ha determinado (Sentencia T-284/94):

Uno de los principios formales de la seguridad jurídica, latente desde el pensamiento de Hooker, es el referente a la determinación legal para todos los actos de las autoridades, así como el de un margen de indeterminación con respecto a los particulares. Así las autoridades sólo pueden hacen (Sic) aquello que esté permitido por la ley -de manera que no pueden crear formas jurídicas-, al paso que los particulares pueden hacer todo aquello que no esté prohibido legalmente. Mientras en el Estado de Derecho el particular es creativo, las autoridades sólo son aplicativas (NFT).

Ahora bien, se podría pensar que el anterior planteamiento de nuestro Alto Tribunal Constitucional es una construcción conceptual encaminada a justificar sus reiterados "ataques" a la seguridad jurídi$\mathrm{ca}$, que tan a menudo se han denunciado. Nada de ello. Por el contrario, el desarrollo jurisprudencial anteriormente citado se enmarca dentro de la más pura tradición romanista, como a continuación se demostrará. En efecto, recordando que la teoría moderna de la libertad así como de la autonomía de la voluntad privada tienen como marco filosófico las ideas de la llustración y el denominado Siglo de las Luces, es imprescindible recordar que la concepción de libertad (y por tanto de seguridad jurídica) que maneja el Código Civil francés (y en consecuencia su homólogo colombiano) es la definida por la Declaración de los derechos del hombre y del ciudadano de 1789 , la cual define la idea de libertad y sus consecuencias legales en sus artículos $4^{\circ}$ y $5^{\circ}$ de la siguiente manera:

Artículo 4. - La libertad consiste en poder hacer todo aquello que no perjudique a otro: por eso, el ejercicio de los derechos naturales de cada hombre no tiene otros límites que los que garantizan a los demás miembros de la sociedad el goce de estos mismos derechos. Tales límites sólo pueden ser determinados por la ley. (NFT)

Artículo 5. - La ley sólo tiene derecho a prohibir los actos perjudiciales para la sociedad. Nada que no esté prohibido por la ley puede ser impedido, y nadie puede ser constreñido a hacer algo que ésta no ordene (NFT).

A su vez, los revolucionarios franceses se basaron en la más típica concepción del Derecho Romano, en el que ocuparon especial preeminencia los tria iuris praecepta (honeste vivere, alterum non laedere, suum cuique tribuere). Los tres preceptos del Derecho son enunciados por primera vez por Ulpiano en sus Institutiones y recogidos posteriormente en el Corpus iuris civilis (D. I, 1, 10, 1 y en I, 1, 1, 3) con la célebre fórmula latina: "Iuris praecepta sunt haec: honeste vivere, alterum non laedere, suum cuique tribuere" (éstos son los preceptos del Derecho: vivir honestamente, no hacer mal a otro y dar a cada uno lo suyo). Esta trilogía es la base de la tradición jurídica romanista (Jiménez, s.f.).

Vemos pues que la idea de libertad como un no hacer (daño) se remonta -cuando menos- a Ulpiano. De hecho, es innegable la influencia que tanto Platón como Aristóteles tuvieron en este jurisconsulto romano. Es por ello que el estrecho vínculo entre indeterminación y seguridad jurídica es perfectamente acorde con nuestras raíces romanas. En realidad, la teoría del neo constitucionalismo poco tiene de revolucionaria; más bien se trata de reivindicar postulados tradicionales que fueron deliberadamente olvidados y escondidos por la jurisprudencia y doctrina del siglo XIX. Así pues, el imperativo de seguridad jurídica está diseñado 
para proteger la libertad de los justiciables que no hagan daño a sus congéneres. En consecuencia, el funcionario estatal no desconoce la seguridad jurídica cuando impide a un particular perjudicar a otro, bien sea por la vía contractual o cuando siendo inevitable el daño, obliga al autor de éste a reparar el perjuicio causado a su víctima. Es por ello que el artículo 16 de nuestra Constitución preceptúa: “Artículo 16. Todas las personas tienen derecho al libre desarrollo de su personalidad sin más limitaciones que las que imponen los derechos de los demás y el orden jurídico".

Moraleja: cuando menos desde la época de Platón hasta nuestros días la seguridad jurídica implica el deber del Estado de impedir que los particulares perjudiquen a sus congéneres. Cuando la Corte Constitucional (en sede de tutela o mediante el control constitucional de una ley) o el juez de responsabilidad impide a un sujeto de derecho perjudicar a su contraparte no atenta contra la seguridad jurídica, sino que, por el contrario, protege este principio rector del Derecho. Es por ello que en más de una ocasión en nombre de la seguridad jurídica se ha permitido la inseguridad jurídica -cuando un tribunal o entidad administrativa permite una ofensa, un mal o daño a un justiciable-. La seguridad jurídica se creó para impedir las arbitrariedades del Estado, no para que éste permitiera a los particulares causarle daño a sus semejantes. Nada de ello desenfoca con el hecho de que la constitucionalización implique la sujeción no sólo de los actos públicos, sino también los privados al imperio de los derechos fundamentales (Carrillo, 2003, p. 236). Es procedente recordar que ya el jurisconsulto Juliano había sentenciado "en aquello que está constituido contra la razón del Derecho, no podemos seguir la regla del Derecho" (D. 1, 3, 15).

\section{LA JURISPRUDENCIA CONSTITUCIONAL, FUENTE DINÁMICA}

La jurisprudencia ha sido definida como el conjunto de providencias dictadas por los altos tribunales que desatando casos iguales decide en forma uniforme (Sentencia C-104/93).

Igualmente, las sentencias de los tribunales han desempeñado un papel importante de adaptación de las reglas a las necesidades de nuestra época actual. Ella no sólo ha aclarado, sino que también ha vivificado numerosas disposiciones del Derecho de la Responsabilidad. De hecho, no ha dudado en tomar grandes libertades (Terre, Simler \& Lequette, 1999) a la hora de dar alcance a las diferentes disposiciones normativas. Muy a menudo el fundamento de tales soluciones audaces radica en las distintas propuestas de los autores a la hora de criticar el Derecho positivo vigente; no es ajeno a la realidad manifestar que más de una propuesta doctrinal de reforma del Derecho Objetivo de la Responsabilidad se ha convertido de facto en una interpretación jurisprudencial de las normas vigentes, precisamente, leyes criticadas por la doctrina.

Es menester señalar que una de las principales características de la posmodernidad jurídica es la crítica que hace contra el culto al formalismo que efectúa la modernidad. Pues bien, este planteamiento tiene aplicación práctica y concreta en relación con el papel que debe desempeñar el juez posmoderno: garantizar la prevalencia de la justicia sobre el culto a las formas. Asimismo, este fin constituye un imperativo constitucional -no se olvide que nuestra Constitución tiene un basamento posmoderno- tal y como la misma Corte Constitucional lo señaló en los siguientes términos (Sentencia C-366/00, expediente D-2541, MP Alfredo Beltrán Sierra):

Una de las funciones del juez dentro del Estado de Social de Derecho, consiste en interpretar, dentro del marco de los principios que rigen éste, los actos y conductas de los individuos a efectos de cumplir en forma cabal su función y dar prevalencia al principio de justicia, que no puede quedar desplazado por el culto a las formas, desconociendo los derechos y garantías reconocidas a las personas. El deber del juez, no puede ser entonces de 
simple confrontación. Su función ha de ser entendida hoy de forma diferente a como lo fue en vigencia del Estado clásico de derecho, pues es un juez que está obligado a interpretar, a deducir, con el objetivo de cumplir en forma adecuada y cabal su tarea, que no es otra que la realización de los derechos de los individuos.

El lector habrá notado la cantidad de ocasiones en que el presente texto ha citado los diferentes pronunciamientos jurisprudenciales emitidos por la Corte Constitucional. No deja de llamar la atención que en un tema perteneciente al Derecho Privado y no al Público, la jurisprudencia de la Sala Civil de la Corte Suprema de Justicia no sea evocada, viéndose desplazada por la de su equivalente constitucional. Aún más: dentro de la visión tradicional -entiéndase moderna- se ha enseñado que la jurisprudencia, al igual que la doctrina y la costumbre, son, ante todo, fuentes auxiliares del Derecho. Sin embargo, tal planteamiento desconoce que en efecto hay un tipo específico de jurisprudencia que tiene carácter obligatorio: la jurisprudencia constitucional.

Semejante aserto podría causar desconcierto en algunos sectores clasicistas del Derecho, precisamente por entender que en un sistema jurídico de corte romanista la ley es fuente primaria, mientras que el resto de fuentes formales son auxiliares $y$, por tanto, de seguimiento optativo por parte del juez. Más aún, cuando el art. 230 de nuestra Constitución -anteriormente citado- establece que la jurisprudencia es un mero criterio auxiliar. Sin embargo, ha llegado la hora de complementar la precedente exposición dedicada a la constitucionalización del Derecho Privado (Supra, la Constitución Política como fuente de Derecho) para verificar que a partir de categorías tradicionales se debe entender que la jurisprudencia constitucional es mucho más que un mero criterio auxiliar y que de hecho comporta fuerza vinculante para el juez de la responsabilidad, así como para el resto de operadores jurídicos, como se demostrará a continuación.

\section{Carácter vinculante de la jurisprudencia constitucional}

La Ley 153 de 1887 establece en su artículo $4^{\circ}$ lo siguiente: "Los principios del derecho natural y las reglas de la jurisprudencia servirán para ilustrar la Constitución en los casos dudosos. La doctrina constitucional es, a su vez, norma para interpretar las leyes" (NFT).

Nótese que la disposición citada habla de "doctrina constitucional" y no de "jurisprudencia constitucional". La razón de semejante precisión radica en el hecho de que la Corte Constitucional goza de la función de ser el intérprete oficial de la Carta Política; en consecuencia, la interpretación jurisprudencial que haga la Corte de nuestra norma de normas constituye la denominada "doctrina", la cual tiene incidencia directa sobre la manera en que el resto de operadores jurídicos deben interpretar la totalidad de normas ordinarias; la razón de este planteamiento la explica en concreto la misma Corte Constitucional, quien frente a este punto manifestó (Sentencia C-083/95, MP Carlos Gavia Díaz):

La disposición transcrita corrobora, además, la distinción que atrás queda hecha entre doctrina constitucional y jurisprudencia. Es apenas lógico que si el juez tiene dudas sobre la constitucionalidad de la ley, el criterio del intérprete supremo de la Carta deba guiar su decisión (NFT).

El anterior planteamiento encuentra claro sustento, además, en el artículo $5^{\circ}$ de la misma ley (153 de 1887), cuyo texto reza: “Dentro de la equidad natural y la doctrina constitucional, la crítica y la hermenéutica servirán para fijar el pensamiento del legislador y aclarar o armonizar disposiciones legales oscuras o incongruentes" (NFT).

En síntesis, la doctrina constitucional es un instrumento no sólo orientador, sino también obligatorio cuando se emplea como elemento integrador, porque en este caso es la propia Constitución (ley suprema) la que se aplica (Senntecia C-083/95, MP 
Carlos Gaviria Díaz). En estrecha concordancia con la presente realidad jurídica, el artículo 243 de la Constitución estipula:

Los fallos que la Corte dicte en ejercicio del control jurisdiccional hacen tránsito a cosa juzgada constitucional.

Ninguna autoridad podrá reproducir el contenido material del acto jurídico declarado inexequible por razones de fondo, mientras subsistan en la Carta las disposiciones que sirvieron para hacer la confrontación entre la norma ordinaria y la Constitución.

Con fundamento en las normas anteriormente transcritas, la misma Corte Constitucional señaló (Sentencia C-104/93, MP Alejandro Martínez Caballero):

Se observa que entre la jurisprudencia de la Corte Constitucional y el resto de jurisprudencia de los demás jueces y tribunales del país -en la que se encuentra la del Consejo de Estado-, existen semejanzas y diferencias.

Las semejanzas consisten en que se trata de un pronunciamiento jurisdiccional con fuerza de cosa juzgada. Las providencias tanto de la Corte Constitucional -art. 21 del Decreto 2967 de 1991-, como del Consejo de Estado que declaren o nieguen una nulidad -art. 175 del código contencioso administrativo- tienen efectos erga omnes, mientras que, en general, las sentencias judiciales sólo tienen efectos inter partes.

Las diferencias estriban en el hecho de que mientras la jurisprudencia de los jueces y tribunales no constituyen un precedente obligatorio, salvo lo establecido en el artículo 158 del código contencioso administrativo (reproducción del acto suspendido). Tales providencias sólo tienen un carácter de criterio auxiliar -art. 230 $\mathrm{CP}-$, para los futuros casos similares, la jurisprudencia constitucional tiene fuerza de cosa juzgada constitucional -art. 243 $\mathrm{CP}-$, de suerte que obliga hacia el futuro para efectos de la expedición o su aplicación ulterior (NFT).

Ahora bien, hasta el presente punto se podría pensar que la única parte vinculante de una sentencia proferida por la Corte Constitucional es la resolutiva, que es en la que se manifiesta si tal o cual norma jurídica es conforme o contraria a la Constitución. Nada de eso: la parte motiva de las sentencias proferidas por el alto tribunal colombiano también obligan a los operadores jurídicos, juez de responsabilidad incluido. Ello por las razones que a continuación se exponen: considerar lo contrario, esto es, que únicamente la parte resolutiva tiene fuerza de cosa juzgada, sería desconocer que admitiendo una norma diferentes lecturas, el intérprete se acoja a lo dispositivo de una sentencia de la Corte Constitucional e ignore el sentido que la Corporación - guardiana de la integridad y supremacía de la Carta-, le ha conferido a dicha norma para encontrarla conforme o inconforme con la Constitución. En respaldo de esta posición se encuentra la tradición jurídica del país, que la misma Corte Constitucional ha recogido en los siguientes términos (Sentencia C-131/93, MP Alejandro Martínez Caballero):

En efecto, la Corte Suprema de Justicia afirmó en 1916 lo siguiente:

"La cosa juzgada ha de hallarse en lo general en la parte definitiva de la sentencia, pero los motivos de ésta carecen de fuerza de fallo, porque son simples elementos de la convicción del juez, que pudiendo ser idóneos en ocasiones, no afectan sin embargo la decisión misma. Empero tiene una excepción este principio, también aceptada generalmente en teoría y en jurisprudencia, y es que cuando los motivos son, no ya simples móviles de la determinación del juez sino que se liga internamente al dispositivo y son como 'el alma y nervio de la sentencia' constituye entonces un todo con la parte dispositiva y participa entonces de la fuerza que ésta tenga. Numerosos son los casos en que sin conexionar los motivos determinantes de un fallo, ella sería incompatible e inejecutable" (Corte Suprema de Jusiticia, Sentencia del 20 de octubre de 1916, p. 250; citada en Sentencia C-131/93) (NFT).

La misma doctrina fue reiterada por aquella corporación en 1928 (Corte Suprema de Justicia, Senten- 
cia del 9 de julio de 1928, p. 550; citada en Setencia C-131/93) y en 1967 (Corte Suprema de Justicia, Sentencia del 17 de septiembre de 1967, pp. 42-43; citada en Sentencia C-131/93). El Consejo de Estado, en providencia de 1981 sostuvo la misma tesis de la cosa juzgada implícita, así (Consejo de Estado, Sentencia del 9 de septiembre de 1981; citada en Sentencia C-131/93):

Considera esta Sala que el pronunciamiento sobre competencia que hizo la Corte en relación con las materias del Decreto autónomo 2617 de 1973 constituye cosa juzgada implícita que, conforme a doctrina reiterada de esta Corporación, debe acatarse, así se compartan o no los fundamentos mismos del citado fallo...

Sobre lo que es la cosa juzgada implícita dijo esta Sala en fallo dictado el 20 de junio de 1979 lo siguiente:

"En un fallo de inexequibilidad, como en cualquiera otra sentencia, hace tránsito a cosa juzgada no solamente lo decidido explícitamente, vale decir, lo expresado en la parte resolutiva, sino también lo implícito en ella. A este respecto dice Carnelutti:

Ello no significa que la cosa juzgada se limite a las cuestiones que encuentre en la decisión una solución expresa: no se olvide que la decisión es una declaración como las demás, en la que muchas cosas se sobreentienden lógicamente sin necesidad de decirlas. Especialmente cuando la solución de una cuestión supone como 'Prius' lógico la solución de otra, esta otra se halla también implícitamente contenida en la decisión (al Ilamado 'Judicato' implícito). Se halla implícitamente consultadas todas las cuestiones cuya solución sean lógicamente necesarias para llegar a la solución expresadas en la decisión. $\mathrm{Si}$, por ejemplo, el juez se pronuncia sobre la resolución de un contrato, afirma implícitamente su validez (Sistema de Derecho Procesal Civil Utena-Argentina 1944 T.I. N 92)... (NFT).

La tesis de la cosa juzgada implícita conlleva de suyo que no sólo lo dispuesto en la parte resolutiva, sino también las razones que fundamentan dicha decisión hagan tránsito a cosa juzgada constitucional. Finalmente, la misma Corte Constitucional señala los criterios para determinar cuáles aspectos de la parte motiva de sus sentencias son de obligatorio cumplimiento, en los siguientes términos (Sentencia C-131/93):

La sentencia de la Corte Constitucional es para un juez fuente obligatoria. Únicamente una parte de sus sentencias posee el carácter de cosa juzgada. Poseen tal carácter algunos apartes de las sentencias en forma explícita y otros en forma implícita. Goza de cosa juzgada explícita la parte resolutiva de las sentencias, por expresa disposición del artículo 243 de la Constitución y goza de cosa juzgada implícita los conceptos de la parte motiva que guarden una unidad de sentido con el dispositivo de la sentencia, de tal forma que no se pueda entender éste sin la alusión a aquéllos. La parte motiva de una sentencia de constitucionalidad tiene en principio el valor que la Constitución le asigna a la doctrina en el inciso segundo del artículo 230: criterio auxiliar -no obligatorio-, esto es, ella se considera obiter dicta. Distinta suerte corren los fundamentos contenidos en las sentencias de la Corte Constitucional que guarden relación directa con la parte resolutiva, así como los que la Corporación misma indique, pues tales argumentos, en la medida en que tengan un nexo causal con la parte resolutiva, son también obligatorios y, en esas condiciones, deben ser observados por las autoridades y corrigen la jurisprudencia. La ratio iuris se encuentra en la fuerza de la cosa juzgada implícita de la parte motiva de las sentencias de la Corte Constitucional, que consiste en esta [sic] Corporación realiza en la parte motiva de sus fallos una confrontación de la norma revisada con la totalidad de los preceptos de la Constitución Política (NFT).

Aún más, corresponde a la misma Corte, en última instancia, señalar los efectos de su propia sentencia: "sólo la Corte Constitucional, de conformidad con la Constitución, puede, en la propia sentencia, señalar los efectos de ésta. Este principio, válido en general, es rigurosamente exacto en tratándose 
de las sentencias dictadas en asuntos de constitucionalidad" (Sentencia C-131/93).

Es por las anteriores razones que nuestro alto tribunal ha establecido que "En síntesis, entre la Constitución y la Corte Constitucional, cuando ésta interpreta aquélla, no puede interponerse ni una hoja de papel" (Sentencia C-131/93). Por consiguiente, si la ley es dura (Supra) más dura es la Constitución Política en virtud del principio de jerarquía de normas y el artículo $4^{\circ}$ de la Carta. Corresponde a nuestra Corte Constitucional salvaguardar la supremacía de la norma de normas en acatamiento de la clásica pirámide kelseniana. Consecuencialmente incumbe al resto de operadores jurídicos (juez de responsabilidad incluido) acatar el desarrollo jurisprudencial efectuado por el alto tribunal y someterse a la cosa juzgada constitucional (artículo 243 de la Constitución), presupuesto del respeto a la jerarquía normativa que debe imperar ya desde el clásico Estado de Derecho.

Con base en lo anterior, la nueva regla en materia de régimen de responsabilidad es clara: Ios principios rectores del derecho de la responsabilidad se entienden incluidos en el valor "justicia", expresamente reconocido por nuestro ordenamiento supremo. A modo de comparación, recordemos que tal valor lo heredamos de la carta española; $y$ de manera correlativa, el Tribunal Constitucional de ese país se manifestó sobre el carácter constitucional de la regla que impone el deber de indemnizar el daño, con fundamento en valores constitucionales, tales como el derecho a la vida digna, la integridad física o la igualdad, entre otros, sentando un principio constitucional en materia de reparación del daño personal, independientemente de la causa que le provoque; o la inversión de la carga de la prueba en cumplimiento del imperativo constitucional de proteger a la parte débil; o el redimensionamiento de la noción de daño moral en aras de tutelar la intimidad personal (De Ángel, 2008, pp. 346 y ss.). Todos estos aspectos abren la puerta a una muy necesaria reforma no legal a nuestro régimen de reparación de daños, en aras de materializar nuestros valores jurídicos supremos.

\section{REFERENCIAS}

Alexy. (2003). Tres escritos sobre los derechos fundamentales y la teoría de los principios. Bogotá: Editorial Uiversidad Externado de Colombia.

Carrillo, J.M. (2003). Tendencias del derecho de las obligaciones. El concepto en el derecho público y el derecho privado. En Estudios de derecho civil, obligaciones y contratos (Tomo I). Bogotá: Editorial Universidad Externado de Colombia.

Cepeda, M.J. (1992). Los derechos fundamentales en la Constitución de 1991. Bogotá: Temis.

De Ángel, R. (2008). Constitución y Derecho de daños. En Neoconstitucionalismo y derecho privado: el debate. Bogotá: Diké.

Dworkin, R. (1977). Taking Rights Seriously. Harvard University Press, Clarendon Press.

Dworkin, R. (1984). Los derechos en serio (M. Guastatvito, trad.). Barcelona: Ariel.

Hart, H.L.A. (1961). The concept of Law. Oxford: Clarendon Press.

Hart, H.L.A. El concepto de Derecho (G. Carrió, trad.). Buenos Aires: Abeledo-Perrot.

Jiménez C., R.M. (Sin fecha). Sobre los principios generales del Derecho. Especial consideración en Derecho español. Recuperado de: http://www. filosofiayderecho.com/rtfd/numero3/1-3.pdf

Rodríguez, C. (2008). La decisión judicial. Bogotá: Siglo del Hombre Editores.

Sentencia C-083/95

Sentencia C-104/93 
Sentencia C-221/94

Sentencia C-366/00

Sentencia No. C-131/93.
Sentencia No. C-549/93

Sentencia No. T-284/94

Terre, Simler \& Lequette. (1999). Les obligations. Paris: Dalloz. 